\title{
Lenition of intervocalic alveolar fricatives in Catalan and Spanish
}

José Ignacio Hualde (University of Illinois at Urbana-Champaign) \&

Pilar Prieto (ICREA - Universitat Pompeu Fabra)

Short title: Lenition of fricatives

José I. Hualde

Dept. of Spanish, Italian \& Portuguese

4080 FLB,

Univ. of Illinois at Urbana-Champaign

Urbana, IL 61801

USA

jihualde@illinois.edu

\section{Lenition of intervocalic alveolar fricatives in Catalan and Spanish}

\begin{abstract}
We offer an acoustic study of variation in the realization of intervocalic alveolar

fricatives in Catalan and Spanish. We consider the effects of phonological
\end{abstract}


inventory (Catalan has a distinction between /s/ and / $\mathrm{z}$ / that Spanish lacks) and position in word.

An analysis of a corpus of Map Task interviews in Catalan and Spanish revealed that Spanish word-medial and initial intervocalic /s/ segments are shorter than in Catalan. Whereas our results are consistent with the predictions of theories incorporating functional principles (i.e. contrast preservation), we also consider other possible explanations of the facts.

The analysis also revealed that Spanish word-final intervocalic /s/ segments are weaker along the two dimensions that we examined (duration and voicing) than their initial and medial counterparts. We suggest that this apparently morphological effect on lenition has an articulatory explanation in terms of gestural coordination.

\section{Introduction}

The phenomenon with which we are concerned in this paper is the synchronic weakening of intervocalic alveolar fricatives in Iberian Spanish and Catalan. A reason to compare Spanish and Catalan is that these are two closely related languages that differ in the phonological status of voiced fricatives: whereas Catalan has a contrast between voiceless /s/ and voiced /z/, Spanish 
lacks the voiced phoneme /z/. We investigate the possible effects of this phonological difference on the phonetic weakening of $/ \mathrm{s} /$ in the two languages.

Contrast preservation has been claimed to be an important principle in phonology (Flemming 1995, Łubowicz 2003), which may condition the phonetic realization of segmental and suprasegmental phonological features (OrtegaLlebaria 2004, Gussenhoven \& Wang 2014, among others). In particular, the claim has been made that lenition processes show an overwhelming tendency to avoid neutralization (Gurevich 2004). The prediction that follows from this theoretical stance is that Catalan would show less weakening of intervocalic /s/ than Spanish.

In addition to inventory-driven effects, a second non-phonetic factor that we want to explore in this study is the possible effect of word-boundaries on intervocalic lenition. Our target tokens are all intervocalic, but differ in the presence of word boundaries. We compare sequences with word-internal /NCV/, word-initial /V\#CV/, and word-final consonants /VC\#V/. As we explain below, word-position interacts with the possibility of having a phonological contrast in Catalan. In principle, The Neogrammarian hypothesis excludes the possibility of having morphological effects at the inception of a sound change (see Joseph 1999, discussed below in more detail). Our view is, however, that predicting a difference between /VC\#V/ and the other two intervocalic contexts, word-initial and word-medial, is not really incompatible with this orthodox position, once we 
consider that there may be a difference in articulatory planning between /CV/

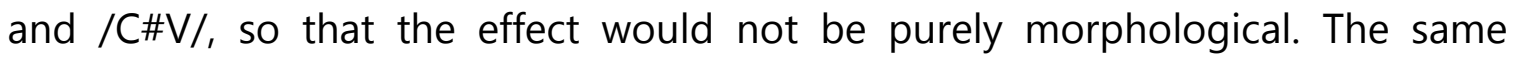
reasoning would not apply, on the other hand, to NCV/ vs. N\#CV/, where gesture coordination can be assumed to be the same.

Before developing our hypotheses, we situate our investigation of /s/ lenition within recent research on intervocalic voicing in Spanish and other Romance languages. The phonetic weakening of intervocalic /s/ in Catalan and Spanish may be considered within a larger phenomenon affecting other voiceless consonants. A number of acoustic studies have shown that the intervocalic voiceless stops /p t k/ have a tendency to voice, and further weaken to approximants, in many Spanish varieties (Torreblanca 1976, Machuca 1997, Lewis 2001, O'Neill 2010, Hualde et al. 2011, Torreira \& Ernestus 2011). For instance, la política 'the politics' may be realized as [laßolíðiya]. From a historical point of view, this is a "second round of voicing" in the evolution form Latin to Romance (Oftedal 1985). This lenition is an incipient, optional phenomenon, much more common in spontaneous speech than in reading style and subject to substantial individual variation (Hualde et al. 2011). Some previous work has shown that, in Spanish, optional intervocalic voicing also affects fricatives, especially /s/ (Torreblanca 1976, Torreira \& Ernestus 2012. For the lenition of /f/ see Blecua \& Rost 2013). In particular, Torreira \& Ernestus (2012) found that over a third of 
tokens of intervocalic /s/ extracted from a corpus of casual Madrid Spanish were realized as voiced during their entire duration.

The optional voicing of intervocalic /p t k/ is also found in Catalan, although perhaps with lesser intensity than in Spanish (see Hualde et al. 2010 for Majorcan Catalan, which is clearly more conservative than Iberian Spanish in this respect). To our knowledge, there has been no systematic study of the synchronic weakening of $/ \mathrm{s} /$ in this language.

In principle, it seems sensible to think that the voicing lenition of intervocalic /s/ may be part of the same phenomenon as the voicing of intervocalic stops. In this respect, we note that the historical voicing of intervocalic consonants in Western Romance ("first round of voicing") affected both stops and fricatives, as show in (1) with Catalan and Portuguese examples:

(1) Voicing of intervocalic obstruents in Western Romance

Lat LUPA $\quad>\quad$ Cat lloba, Port loba 'she-wolf'
Lat AMİCA $\quad>\quad$ Cat, Port amiga 'friend, fem.'
Lat CASA $\quad>\quad$ Cat, Port ca/z/a 'house'

On the other hand, however, there are important differences between stops and fricatives. Whereas the voicing of intervocalic plosives can be taken as 
a unidirectional phenomenon, e.g. /ata/ > /ada/ is common in historical evolution, but /ada/ >/ata/ is not (but see Pape \& Jesus 2011 for European Portuguese), strident fricatives are subject to competing pressures, with both the voicing of intervocalic fricatives, e.g. /asa/ > /aza/, and the (unconditioned) devoicing of sibilants, /z/ > /s/ being natural, unremarkable phenomena. In fact, regarding examples like those in (1), in Spanish the evolution has been just like in Catalan and Portuguese for intervocalic $/ \mathrm{p} \mathrm{t} \mathrm{k/,} \mathrm{but} \mathrm{there} \mathrm{has} \mathrm{been} \mathrm{a} \mathrm{round-trip}$ evolution for intervocalic /s/, which was voiced in Old Spanish, but devoiced again some centuries later, Lat /kása/ > OSp /káza/ > ModSp /kása/ (see, e.g., Penny 2002:98-103). Voiced fricatives and affricates also underwent devoicing in several other Ibero-Romance languages, including varieties of Valencian Catalan (Wheeler 2005:23). (On reversible and nonreversible sound changes in Romance, see Recasens 2002).

The production of voiced fricatives, especially voiced strident fricatives such as $/ z /$ and $/ 3 /$, is subject to opposing aerodynamic constraints, since the maintenance of voicing and the generation of a turbulent airstream make contradictory demands (Ohala 1983: 201-202). To solve this conflict, phonologically voiced fricatives may be produced as partially or completely devoiced, as it frequently happens in English (Smith 1997). Diachronically, this may lead to the recategorization of voiced fricatives as voiceless (see Fontanella 
de Weinberg 1979, 1987: 144-150, Rohena-Madrazo 2013 for the devoicing of /3/ in Argentine Spanish). The other solution to the incompatibility between voicing and stridency is to maintain voicing at the cost of reducing friction (Solé 2002). This solution is also widely attested both in diachronic processes and in

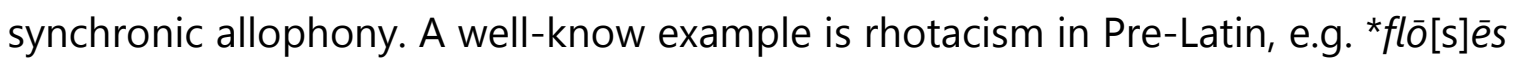
> *flō[z]ēs > flō[r]ēs 'flowers' (Allen 1978: 35, Trask 1996: 78-82). (Rhotacism of /s/ before a voiced consonant is found dialectally both in Spanish, see Moreno Fernández 1996: 218, and in Catalan, see Recasens 1996, Pons Moll 2007: 157167). Assimilation in voice of $/ \mathrm{s} /$ in the intervocalic context thus competes with other constraints disfavoring [z]. Given these differences in the voicing of stops and fricatives, it is not obvious that the same pattern of lenition should be predicted for intervocalic $/ \mathrm{s} /$ as has been found in other studies that have examined intervocalic /p t k/ in the same languages. Thus, although we see the voicing of intervocalic /s/ as part of the same phenomenon that affects voiceless stops in Spanish and Catalan, we do not necessarily expect to find the same results as in studies that have examined the voicing of $/ \mathrm{p} \mathrm{t} \mathrm{k/.} \mathrm{It} \mathrm{seems} \mathrm{that,} \mathrm{in}$

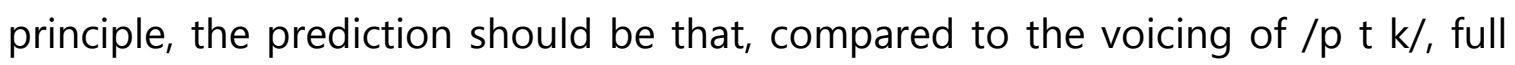
voicing of /s/ (as opposed to its partial voicing) would be less common, because of the opposing aerodynamic constraints that we have mentioned. However, we note that Torreira \& Ernestus (2012) find a percentage of fully voiced tokens of 
intervocalic /s/ (34\%) that is very similar to that reported in Torreira \& Ernestus (2011) for intervocalic /p t k/ (32.7\%) in the same corpus of casual Madrid Spanish. In this paper, we are not able to further test these facts, since we are only concerned with alveolar fricatives.

\section{Main research questions and predictions}

This study addresses two main research questions, one involving a comparison between Spanish and Catalan /s/ and testing the effects of preservation of phonological contrast in the weakening of this consonant, and another one establishing a comparison of morphophonological contexts within the same language, which tests the effects of word boundaries. Both questions thus involve the possible effect of non-phonetic (i.e. phonological or morphological) factors on phonetic lenition.

In Spanish, there is no voice opposition among the fricatives. All fricatives are phonologically voiceless, although a well-documented phenomenon is their voicing before a voiced consonant, e.g. /mísmo/ [mízmo] 'same' (see Schmidt \& Willis 2011 for a recent study).

In Catalan, on the other hand, there is a phonological contrast between /s/ and /z/. This phonemic contrast is, however, restricted to onset position and essentially limited to the word-internal intervocalic position (e.g. caça /kásə/ 
'hunt' vs casa /kázə/ 'house'). Word-initially there is also a phonemic contrast, but /z/ is only found in a handful of, mostly technical, words, e.g. zero 'zero', zona 'zone' (for which devoicing is common, Recasens 1993: 173). Word-finally, the contrast is neutralized, and [s] and [z] are said to be found in complementary distribution: [s] appears before a voiceless segment or pause, e.g. mé[s] temps 'more time', mé[s] 'more', and [z] before a voiced consonant or vowel, e.g mé[z] dies 'more days', mé[z] amics 'more friends' (see, e.g., Wheeler 2005: 148-149, 162-163).

Our first research question is thus related to contrast preservation as a possible factor in the phonetic realization of /s/ in Catalan vs. Spanish. If contrast preservation acts as a phonological restriction in the weakening phenomenon, we would expect for word-initial or word-medial /s/ to show less voicing and greater duration in Catalan, where it contrasts with /z/ phonemically, than in Spanish, where it does not. Regarding the predicted effects on duration, as is well known, there is an inverse correlation between voicing and duration, so that phonologically voiced obstruents are shorter than their phonologically voiceless counterparts (Lehiste 1990; for /s/ and /z/ in English, see Smith 1997).

As explanations for phonetic patterns, inventory-driven, functional principles are, by their very nature, more controversial than articulatory, acoustic or aerodynamic factors. Our view is that one way to determine the efficacy of 
such principles in explaining synchronic phonetics and sound change is by conducting comparative studies like the present one and examining, first of all, whether the facts are compatible with the predictions stemming from the functional principle and, secondly, whether there could be alternative explanations. The evaluation of the cumulative evidence of a number of studies of this type could then be used to decide the question of the reality of contrast preservation and similar principles. That is, we take the principle of preservation of contrast as a hypothesis to be tested.

Our second research question concerns word position. As mentioned in the introduction, the Neogrammarian view excludes the possibility 0 morphological boundaries as a conditioning effect in sound change. As Joseph (1996:6) explains, "if sound change is a purely mechanical adjustment in pronunciation triggered by the phonetics of connected speech, that is by purely physiological (articulatory or perceptual) effects, then it follows that whenever those conditions obtain - whether in a word or in a phrase, whether in wordmedial or in word-initial position, whether at a morpheme boundary or within a monomorphemic word-the change would take place."

Several recent studies have compared the realization of phonological stops in the contexts /VCV/ and /V\#CV/ in Spanish and other Romance languages. In general, the difference between these two contexts appears to be 
small or non-existent and, thus, in accordance with the Neogrammarian hypothesis of no morphological conditioning in lenition processes. Hualde et al. (2011), did not find an effect of word boundaries on either the voicing of intervocalic $/ \mathrm{p} \mathrm{t} \mathrm{k/} \mathrm{or} \mathrm{the} \mathrm{degree} \mathrm{of} \mathrm{constriction} \mathrm{of} / \mathrm{p} \mathrm{t} \mathrm{k} \mathrm{b} \mathrm{d} \mathrm{g/} \mathrm{in} \mathrm{Iberian}$ Spanish. Eddington (2011) studied the allophony of /b d g/ in Spanish, including speakers from several dialects, and reported that intervocalic $[\beta]$ and [ð] were less constricted when word-medial than when word-initial, but he found no effect for [y]. Another study of the allophony of /b d g/ in Spanish, Carrasco et al. (2012), found a small statistical effect of word-boundaries on the degree of constriction of these consonants in Costa Rican Spanish, but these authors did not find this effect in their Madrid Spanish corpus. Hualde \& Nadeu (2012), examined the weakening of intervocalic $/ \mathrm{p} \mathrm{t} \mathrm{k} /$ in Rome Italian and reported comparable amounts of weakening in word-medial and word-initial position.

The studies just reviewed, on the allophony of $/ \mathrm{p} \mathrm{t} \mathrm{k/} \mathrm{and} / \mathrm{b} \mathrm{d} \mathrm{g/,}$ considered only the presence of a word boundary immediately before the consonant; that is, they compared/VCV/ with N\#CV/. This is understandable since the consonants that were examined are rare word-finally in Spanish (and Italian). By extending the investigation to $/ \mathrm{s} /$, on the other hand, we can also

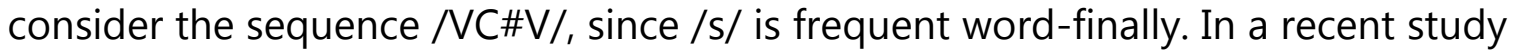
of casual Madrid Spanish, Torreira \& Ernestus (2012) did, in fact, find greater 
lenition of $/ \mathrm{s} /$ in word-final intervocalic position than in other intervocalic contexts.

Our hypothesis, only in apparent disagreement with the Neogrammarian view, is that is that intervocalic /s/ will be more reduced word-finally, $/ \mathrm{Vs} \# \mathrm{~V} /$, than in other positions, as Torreira \& Ernestus (2012) found, resulting in shorter duration and more voicing. The disagreement with the Neogrammarian view is, however, only apparent. We suggest that the difference between $/ \mathrm{Vs} \mathrm{V} /$, on the one hand, and / $\mathrm{VsV} /$ and $/ \mathrm{V \# sV/}$ on the other, is not purely morphological, but also involves differences in articulatory plans. In word-final position, lexical syllabic affiliation gives a different gestural coordination than in /VsV/ and

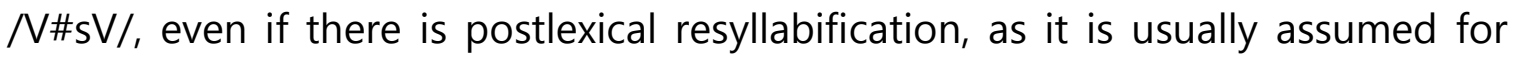
Spanish.

Besides the results in Torreira \& Ernestus (2012), other well-known facts of Spanish also show that in this language consonants tend to be weaker in wordfinal position, even when they are prevocalic. In particular, in addition to possible voicing and reduction in duration, another common form of lenition of $/ \mathrm{s} /$ in many Spanish varieties, including, to some extent, Madrid Spanish, is its aspiration and deletion. Most commonly across Spanish varieties the aspiration and/or deletion of /s/ affects this segment in syllable final position. Nevertheless, in many Spanish dialects with frequent aspiration, word-final $/ \mathrm{s} /$ is subject to 
aspiration and deletion even when it precedes a vowel, and, presumably, is resyllabified as an onset (Harris 1983). That is, in prototypical aspirating dialects, /s/ may be realized as [h] in, for instance, más oro 'more gold', but not in masa 'dough; mass', where it is word internal. (There are also dialects where wordinternal and word-initial prevocalic /s/ is also subject to lenition, see, e.g., Lipski 1986. For recent studies of lenition of $/ \mathrm{s} /$ in dialects with a high incidence of aspiration, see, among others, Brown 2010, File-Muriel \& Brown 2011). We use these facts, from Spanish dialectology, as motivation for the hypothesis of greater weakening in $/ \mathrm{Vs} \# \mathrm{~V} /$ than in $/ \mathrm{VsV} /$ or $/ \mathrm{V \# s} \mathrm{V} /$ also when $/ \mathrm{s} /$ is produced as an alveolar fricative. In the discussion section we return to the topic of /s/ aspiration and its relation to the phenomenon that we investigate in our study.

It should be noted that, in Madrid Spanish, aspiration of $/ \mathrm{s} /$ is not uncommon before certain consonants, but it is infrequent in the prevocalic Ns\#V/ context. Regarding its sociolinguistic distribution, aspiration of /s/ in Madrid Spanish is especially rare in the speech of educated women, which is the demographic group to which all the participants in our study belong. In a sociolinguistic study of /s/ aspiration in Madrid Spanish, Momcilovic (2009: 44) reports less than $3 \%$ of aspirated tokens of $/ \mathrm{s} /$ in the context $/ \mathrm{s} \# \mathrm{~V} /$ in the conversational speech of educated female speakers, who are the most conservative speakers in this respect. Our hypothesis is, again, that even if word- 
final /s/ is realized as an alveolar fricative (and would be coded as notaspirated in a perceptual sociolinguistic study), it may be relatively reduced in comparison to word-initial and word-medial prevocalic tokens.

Regarding word-position effects, then, we expect /VsV/ and / $\# s \mathrm{~V} /$ to pattern together and $/ \mathrm{Vs} \mathrm{V} /$ to undergo greater lenition. As we have explained, we expect that morphological boundaries will have an effect on pronunciation only if they affect articulatory planning.

\section{Methods}

3.1. Participants and speech materials

For this study we have analyzed audio recordings of directed conversational speech (Map Tasks) that were previously collected for unrelated projects, the Interactive Atlas of Catalan Intonation (Prieto \& Cabré 2007-2012) and the Interactive Atlas of Spanish Intonation (Prieto \& Roseano 2009-2013). We have analyzed 13 Map Tasks for Central Catalan (26 speakers) and 8 Map Task for Madrid Spanish (8 speakers). All participants of both languages were educated women between twenty and fifty years of age who grew up in the region where the recording took place. The audio recordings, as well as orthographic transcriptions and the maps used for the task, can be accessed from the corresponding Atlas webpages. 
The dataset used for this investigation consisted of conversational speech that was recorded (for the interactive atlas of intonation of each of the two languages) by having pairs of speakers in each language perform a Map Task. The Map Task methodology is a well-established procedure for obtaining semispontaneous, unscripted speech (Brown et al. 1983, Anderson et al. 1991). In a Map Task, speakers are recorded in pairs as they perform together a goaloriented activity.

Each of the two participants in each recording had a map of an imaginary town including buildings and other specific elements such as fountains and monuments. A route was drawn on the map of one of the two participants, who had the role of instruction-giver. A version of the same map held by the other participant differed from that of the instruction-giver in that it did not show the route to be followed, in addition to several other details. Differences in details between the two maps are intended to elicit discussion.

The total duration of the 13 Catalan Map Task dialogs is 94 minutes, distributed as follows, by the name of the town where the data were collected: Banyoles (2 Map Tasks, 20 minutes), Barcelona (2 minutes), Berga (4 minutes), La Garriga (7 minutes), Manresa (7 minutes), Mataró (11 minutes), Ripoll (4 minutes), Santa Coloma (5 minutes), Solsona (7 minutes), Valls ( 8 minutes), Vic (8 minutes) and Vilafranca del Penedès (6 minutes). These are all towns located in the Central 
Catalan area. As mentioned before, both participants in each recording were natives of the town where the recording took place. The total duration of the 8 Madrid Spanish Map Task dialogs adds up to a total of 60 minutes. All Madrid speakers were living in Madrid and were born either in Madrid or in the surrounding area within the province.

In the selection of participants and speech materials we have been constrained by the availability of recorded data, since, as mentioned, our materials are from preexisting corpora. Nevertheless, in our estimation, the selected materials are fully adequate for the comparison that we want to establish between Madrid Spanish and Central Catalan. All speakers of the two languages are educated women and the speech task in which they engage is the same. This provides an important control. In the case of Catalan, a factor to consider is bilingualism. Different speakers may have different degrees of dominance in Catalan and Spanish or may use the two languages with different frequency. Although the towns where the interviews were conducted vary in their size and their overall social use of the two languages, all speakers that were recorded for the Interactive Atlas of Catalan Intonation were selected because they were strongly dominant in Catalan. 
An additional advantage of using these Spanish and Catalan corpora for our study is that the data are available to other researchers for replication and further testing.

\subsection{Data segmentation and coding}

Data segmentation was performed with Praat (Boersma \& Weenink 2013). We labeled all instances of intervocalic /s/ and / $\mathrm{z} /$ in Catalan and all instances of intervocalic /s/ in Spanish. That is, for Catalan all intervocalic instances of $\langle-$ ç->, $<-s s->,<(-) c->$ before $<\mathrm{i}$, e $>$ and $\langle$ s-> were labeled as /s/ (e.g. passo 'I pass', edificic 'building', podria semblar 'it could seem', no examples containing <ç> were found); all instances of $\langle-\mathrm{s}->$ and $\langle\mathrm{z}>$ were labeled as /z/ (e.g. gasolinera, no instances of orthographic $\langle z\rangle$ were found); and word-final $\langle-s\rangle$, $\langle-c ̧\rangle$ were labeled as /S/ (non-contrastive alveolar fricative, e.g. tires amunt 'you go up'). For Madrid Spanish, the orthography/phoneme correspondence is straightforward: all intervocalic instances of $\langle\mathrm{s}\rangle$, and only those, were labeled as $/ \mathrm{s} /$.

Regarding Catalan, Recasens (1993: 173-175) points out that there is some dialectal or individual variation in the pronunciation of some specific lexical items as containing /s/ or /z/. In every case, we have followed the phonological category suggested by the standard spelling of the word for our labeling. We can 
thus not discard the possibility that a few tokens may have been misclassified with respect to the phonological intention of the speaker.

We discarded tokens that were disrupted by laughter, disfluencies and intrusive overlapping speech, as well those surrounded by voiceless vowels. A total of 974 tokens of intervocalic /s/ and /z/ were labeled for the Central Catalan corpus and a total of 648 tokens of intervocalic /s/ were labeled for the Madrid Spanish corpus.

Segmentation was done manually in PRAAT. To determine the initial and final boundaries of the fricative we considered the onset and offset of aperiodic energy in the sound wave. The segmentation of all sound waves, both Catalan and Spanish, was performed by the same research assistant, who was not informed of the specific research hypotheses. Given the fact that all the data from both languages were segmented by the same person using the same criteria, we are confident about the reliability of the segmentation procedure. Tokens were also tagged as as Initial, Medial or Final in the word, as shown in (2) with Spanish examples from the corpus:

(2) Examples of intervocalic /s/ tokens in Spanish example Initial $\quad \mathrm{V \# s \vee}$ como si 'as if' 


\begin{tabular}{|c|c|c|c|c|}
\hline Medial & $=$ & Vs V & cas $a$ & 'house' \\
\hline Final & $=$ & $\mathrm{Vs} \# \mathrm{~V}$ & más abajo & dow \\
\hline
\end{tabular}

The data were subjected to analysis using both binary and continuous parameters. First, segmented tokens were labeled as fully voiced if they presented regular pulses and uninterrupted pitch in the PRAAT display. This was done by visual inspection. This allowed for a binary classification of tokens as either fully voiced or not. Secondly, two types of information were automatically extracted from the textgrid. One type of information that was extracted is fricative duration, i.e., the distance in time between the onset and the end of aperiodic energy, signaling friction. The second type of information that was obtained is the percentage of "voiced frames" within the target segments. For this we used a script written by Paul Boersma, analyseFricatives.praat, which is included as an appendix in Rivas (2006). Using this algorithm, frames with a local harmonics-to-noise ratio above $0.45 / 0.55(=-0.9 \mathrm{~dB})$ are regarded as voiced. The script returns a value of 1 when all frames within the segment show a harmonicsto-noise ratio above this threshold. A value of 0 indicates that no frames within the segment were classified as voiced by the algorithm. In this script 30 milliseconds of the vowel are taken into account at both sides of the fricative for 
the "voiced frames" report. For this reason the value that is returned is never zero in our data.

We have used of this script because it makes the results more reproducible, since the pitch floor and ceiling and all other settings are under full control. The script provides a report of the percentage of frames that are strongly voiced.

\subsection{Statistical analysis}

For all statistical analyses, we used mixed-effects linear regression models (GLMMs) with SPSS. We applied the same models to two main response variables ("voiced frames" and duration). In both analyses, the model included word Position (with three levels: (word)-Initial, (word)-Medial, and (word)-Final), and Language (with two levels: Catalan and Spanish), as fixed factors, and Speaker and Word identity as random factors. We are concerned with the fixed effects (which were explored separately), plus the potential interactions between word Position and Language. Only statistically significant predictors, as well as significant interactions, are retained in the reported models.

\section{Results}

4.1. Number of fully voiced tokens 
Full voicing of intervocalic /s/ is relatively uncommon in our data. In our Madrid Spanish corpus, only $8.3 \%(N=53)$ of all analyzed tokens of $/ \mathrm{s} /(\mathrm{N}=648)$ were manually identified as fully voiced (which coincides exactly with the number of tokens for which the script returned a value of 1 under 'voiced frames'): Initial $=15 / 126(11.9 \%)$, Medial $=22 / 349(6.3 \%)$, Final $=17 / 119(14.3 \%)$. Figure 1 shows the distribution of fully voiced tokens of /s/ by position in Spanish. The greatest percentage of fully voiced tokens is thus found word-finally.

Figure 1

The percentage of fully voiced tokens that we have obtained is substantially lower than the 34\% reported in Torreira \& Ernestus (2012). The difference between the results of both studies is most likely to be attributed to the more casual style that those authors analyzed (in addition to methodological differences between the studies). However, it is important to note that Torreira \& Ernestus (2012) report a high degree of inter-speaker variation, so that this may also be a factor. 
u In the case of Catalan, the percentage of fully voiced intervocalic /s/, excluding word-final intervocalic sibilants, is much lower, only 4.1\%: Initial 7/256 (2.7\%), Medial 13/230 (5.6\%), see Figure 2.

Figure 2

To complete the picture, we must consider the realization of /z/ and wordfinal sibilants in Catalan. As mentioned before, although in Catalan a /s/-/z/ contrast obtains both word-initially and word-medially, word-initial /z/ is found in only a handful of words. As it happens, in our corpus no instances of word-initial /z/ were found. All references to /z/ in Catalan will thus be to word-medial intervocalic tokens. For word-final tokens, where the voiced/voiceless contrast does not obtain, we use the symbol / $S /$, as already mentioned. Inspection of the data shows that both /z/ and /S/ were very often partially devoiced, although fully voiced realizations were more common than partially devoiced ones for both /z/ (59.4\%) and /S/ (60\%). See Figure 3.

Figure 3 


\subsection{Voiced frames}

In the presentation of the voiced frames and duration results, descriptive graphs (boxplots) will be followed by more detailed statistical analyses.

The boxplots in Figure 4 show the mean percentage of voiced frames of intervocalic $/ \mathrm{s} /$ tokens in Spanish and of $/ \mathrm{s} /, / \mathrm{S} /$ and $/ \mathrm{z} /$ tokens in Catalan (ranging from 0 to 1 ), as a function of the position of the consonant within the word (initial, medial, final) in the Spanish and Catalan Map Task corpora. In the boxplot graphs, the horizontal line within the boxes represents the median of the entire distribution, and the boxes display the interquartile range, i.e. observations between the 25th and the 75th percentiles. Whiskers extend to the most extreme of the observations lying no further away than 0.5 of the length of the box. Observations beyond those points are outliers.

Let us comment the results in Figure 4 separately by the potential effects of word position and language.

Regarding the effects of word position, the most obvious effects are apparent in Catalan. As expected, the highest values of voiced frames correspond to the underlying word-medial / $z /$ in Catalan and to word-final intervocalic NS\#V/. Thus, our results confirm the traditional phonological understanding of the facts; namely, that in Catalan word-final sibilant fricatives are realized as voiced when followed by a vowel in the next word. A phonological interpretation 
is that the neutralization between /s/ and / $\mathrm{z} /$ in word-final position is manifested as phonemic / $z$ / when a vowel follows in the speech chain.

For Spanish, the boxplots show that word-final intervocalic /s/ (/Vs\#V/) is somewhat more voiced than word-medial or word-initial /s/ (/VsV/ and /V\#sV/).

On the other hand, word-final /s/ in Spanish is clearly not as voiced as the corresponding segment in Catalan. Unlike in Catalan, one cannot speak of a phonological rule of voicing for word-final /s/ before a vowel.

Figure 4

In order to investigate the effects of the different factors on /s/-voicing in a single statistical analysis for both languages, we eliminated the Catalan underlying / $z$ / tokens (medial_z in the graph) from the data. We fitted a mixedeffects regression model (GLMM) to the data set, considering the proportion of voiced frames as a response variable, Position in the word (Initial, Medial, Final) and Language (Catalan, Spanish) as fixed factors, and Speaker and Word identity as random factors. A main effect for Position in the word, $F(2,1.289)=139.794, p$ $<.001$, was found, as well as a marginal main effect of Language, $F(2,1.289)=$ 
3.660, $p=.056$, and a significant interaction between Language and Position in the word, $F(2,1.289)=56.254, p<.001$, meaning that the effect of word position was different across the two languages.

To investigate the direction of the interaction Language $\mathrm{x}$ word Position, Bonferroni post-hoc pairwise comparisons were extracted from the model. On the one hand, these comparisons show that voice ratios of intervocalic /s/ are significantly different between the two languages, but only in final position (Catalan vs. Spanish, at $p<.001$ ). For Catalan, we find significant differences in voice ratios between the three pairs of word positions. As expected, the greatest amount of voicing is found for word-final, non-contrastive /S/: Final vs. Initial, at $p<.001$; Final vs. Medial, at $p<.001$. In addition, word-medial consonants have more voicing than initial ones: Initial vs. Medial, at $p<.001$. For Spanish, the only comparison that reaches significance, at $p<.001$, is Final vs. Medial, with final consonants being more voiced. The greater voicing of word-final consonants is in agreement with the findings in Torreira \& Ernestus (2012).

\subsection{Duration}

The boxplots in Figure 5 show the duration (in ms.) of intervocalic /s/ in Spanish and intervocalic /s/ and /z/ in Catalan as a function of the position of the consonant within the word (initial, medial, final) in the Spanish and Catalan data 
(indicated on the $x$ axis). As before, notice that 'medial_z' represents the wordmedial phonological /z/ category in Catalan.

Considering first the Spanish data, visual inspection of the boxplots shows that in Spanish word-final intervocalic /s/ (in /Vs\#V/) is shorter than word-medial or word-initial /s/ (in /VsV/ and /V\#sV/).

In the Catalan data, as expected, underlying word-medial /z/ and final intervocalic /S/ (/VS\#V/), display the shortest durations.

The comparison between Spanish and Catalan indicates that word-initial and word-medial intervocalic /s/ are shorter in Spanish than in Catalan.

Figure 5

The significance of the comparisons was tested via a regression analysis. As before, in order to investigate the different sources of variability affecting the duration of intervocalic $/ \mathrm{s} /$ in a single analysis for the two languages, we eliminated the Catalan underlying / $z /$ tokens (medial_z in the graph) from the data set. We fitted a mixed- effects regression model (GLMM) to this data set, considering the variables in section 2.4 (i.e. Duration as response variable, Position in the word (Initial, Medial, Final) and Language (Catalan, Spanish) as 
fixed factors, and Speaker and Word identity as random factors). Regarding the fixed factors, a main effect for Position in the word, $F(2,1.267)=139.794, p$ $<.001$, was found, as well as a significant interaction between Language and Position, $F(2,1.267)=39.460, p<.001$, meaning that the effect of word Position was different across the two languages.

To investigate the direction of the interaction Language by Position, Bonferroni post-hoc pairwise comparisons were extracted from the model. These comparisons show that, on the one hand, the duration of intervocalic /s/ is significantly different in Catalan vs. Spanish, across the three word positions. In Final position, Catalan word-final /S/ presents shorter duration than Spanish /s/ ( $p$ <.001). In Medial position, on the other hand, Catalan /s/ is longer than Spanish /s/ $(p<.001)$. In Initial position as well, Catalan /s/ is longer than Spanish $/ s /(p<.001)$.

The comparisons among positions within each of the two languages do not return identical results. In Catalan, we find a significant difference in duration between the three pairs of word positions (Final vs. Initial, at $p<.001$, Final vs. Medial, at $p<.001$, and Initial vs. Medial at $p<.001$ ). From longest to shortest the duration hierarchy is Initial > Medial > Final. Nevertheless, regarding the Initial vs. Medial comparison, some caution is in order in the interpretation of this 
significant result, since the boxplots in Figure 4 show a great degree of overlap between the two groups.

In Spanish, on the other hand, only two comparisons are significant in our statistical analysis, namely Final vs. Initial, at $p<.001$, and Final vs. Medial, at $p$ $<.001$. That is, in Spanish there is no difference in duration between word-initial and word-medial tokens of $/ \mathrm{s} /$, but word-final tokens are significantly shorter than the rest. The duration ranking that we find in Spanish is, thus, Initial, Medial $>$ Final. The shorter duration of final /s/ in Spanish is consistent with the finding, reported above, that this is also the position that shows the greatest amount of voicing.

In sum, the regression modeling of the duration results points to two main conclusions, namely, (a) that intervocalic /s/ durations pattern differently in Spanish and in Catalan in the three word positions, with /s/ being longer in Catalan than in Spanish, except that word-final Catalan /S/ is shorter than wordfinal Spanish /s/; and (b) that, within each of the two languages, consonants are shortest in final position. This is true both in Catalan, where final sibilants are phonologically neutralized in voice, and in Spanish. In Catalan, initial /s/ is slightly longer than medial $/ \mathrm{s} /$, which in turn is longer than final $/ \mathrm{S} /$. In Spanish, $/ \mathrm{s}$ / durations in word-final position are significantly shorter than in word-medial and 
word-initial position. There is no difference between initial and medial tokens of /s/ in Spanish.

These results lend initial support both to the hypothesis of less lenition under phonemic contrast in Catalan and to the hypothesis of greater lenition in word-final position.

\section{Results summary}

Our study of lenition of alveolar fricatives in Spanish and Catalan has produced two main findings. Regarding the Catalan vs. Spanish comparison, our results show that reduction of (non-word-final) intervocalic $/ \mathrm{s} /$ is rather more pervasive or intense in Madrid Spanish than in Central Catalan. In particular, both word-initially and word-medially, intervocalic /s/ is significantly longer in Catalan (where it contrasts with /z/) than in Spanish (which has no /z/). Also, about twice as many fully voiced tokens of /s/ were found in Spanish as in Catalan.

Our second research question was related to the possible effects of wordboundaries on lenition. Our main finding in this respect is that intervocalic $/ \mathrm{s} /$ is weaker word-finally than in other positions in the word, as manifested by our duration and voicing measurements. This is true both in Catalan and in Spanish. In Catalan this is an unremarkable finding, since /s/ and /z/ neutralize word-finally and the result of the neutralization before a vowel-initial word is generally taken 
to be voiced. Interestingly this is also true in Spanish, where intervocalic /s/ is shortest and has the greatest amount of voicing in word-final position (although, regarding voicing, the statistical analysis returned a significant result only for the Final vs. Medial comparison), including the greatest percentage of fully voiced realizations. As mentioned, this is in agreement with the findings in this respect in Torreira \& Ernestus (2012). As these authors note, this result, which we have replicated, is also consistent with a tendency for word-final /s/ to be aspirated or elided in many Spanish dialects, even when, as in our study, it precedes a vowel in a following word.

In the next section we consider possible explanations for our findings, regarding differences between the two languages and across positions in the word.

\section{Discussion}

6.1. Realization of intervocalic /s/ in Spanish vs. Catalan

A main finding of our study is that intervocalic /s/ has a stronger, less lenited realization in Catalan that in Spanish. Catalan intervocalic /s/ is longer than in Spanish and is less frequently realized as fully voiced. These results are as predicted by contrast preservation theory (e.g. Gurevich 2003). In this view, the explanation for the stronger realization of intervocalic /s/ in Catalan than in 
Spanish is that in Catalan /s/ is in phonemic contrast with /z/. Maintenance of the phonological contrast would disfavor lenition.

The role of functional principles such as contrast preservation, dispersion and functional load in sound change and synchronic phonology remains controversial. One reason for skepticism regarding the relevance of a principle of contrast preservation is that phonemic neutralization is, in fact, rampant in phonological evolution (see, e.g. Hock 1991: 150-151). For a recent defense of functional principles in sound change, see, however, Wedel (2012), Wedel, Kaplan \& Jackson (2013). See also Boersma (1998) on constraint interaction in functional phonology.

Whereas the difference that we find between Catalan and Spanish is consistent with the principle of contrast preservation, we must consider whether there could be alternative explanations of the facts that do not require appeal to functional principles.

A similar case to that studied in this paper is presented by the allophonhy of $/ b /$ in different Catalan dialects, which has been the object of recent investigation. Some Catalan dialects, such as Majorcan Catalan have a phoneme $/ \mathrm{v} /$ that is not present in most other Catalan varieties. It has been noted that in dialects with a /v/-/b/ contrast, the phoneme /b/ tends to be realized as a voiced stop [b] in contexts where dialects without this contrast it is generally lenited to 
an approximant [ß] (Rafel 1976: 62, Recasens 1971/1975, 2009: 131-132). Several authors have explained this fact by appealing to the principle of contrast preservation (Recasens 1991, Wheeler 2005). In a recent study employing acoustic correlates of degree of constriction, Hualde, Nadeu \& Simonet (2010) find that, indeed, /b/ in contexts of lenition is more constricted in Majorcan than in Central Catalan, as other authors had observed. In addition, within Majorcan Catalan, /b/ is more constricted than $/ \mathrm{d} /$ and $/ \mathrm{g} /$.

As an alternative to contrast preservation, the authors suggest that the explanation for the difference between the two dialects could also be that Majorcan Catalan preserves a less advanced stage in the historical weakening of intervocalic stops. They appeal to aerodynamic explanations to account for the difference across places of articulation. Recasens (2014:106-107) also discusses several possible explanations, besides contrast preservation, that may account for the allophony of $/ b /$ in different Catalan varieties with and without an independent phoneme /V/. In general, before accepting the validity of a functional principle, it seems sensible to consider whether there could be alternative explanations.

Here we will thus consider other reasons that may explain the difference between Catalan and Spanish that we find. In the case at hand, it is important to notice that the reason why the two languages differ at the phonological level in 
this respect is precisely that modern Spanish has given up an older contrast between /s/ and / $\mathrm{z}$ / (as mentioned in section 1), we cannot then exclude the possibility that Spanish /s/ is weaker because it derives diachronically from the merger of earlier /s/ and /z/.

In addition, at this stage in our investigation, we cannot exclude the possibility that Spanish may simply display a greater tendency than Catalan for all voiceless obstruents to undergo reduction, regardless of other considerations. In this respect, it seems relevant to note that Hualde, Simonet \& Nadeu (2010), in an unpublished study, report a considerable difference between Iberian Spanish and Majorcan Catalan in the extent to which intervocalic /p t k/ undergo voicing: in their Spanish corpus, $36 \%$ of all tokens of intervocalic $/ \mathrm{p} \mathrm{t} \mathrm{k/} \mathrm{were} \mathrm{realized} \mathrm{as}$ either fully or partially voiced vs. only $17 \%$ in a similar corpus of Majorcan Catalan. Central Catalan remains to be examined.

In order to determine the possible role of contrast preservation in the lenition of $/ \mathrm{s} /$, future work could thus investigate the production of all shared voiceless fricative and plosive phonemes / $\mathrm{s} \mathrm{p} \mathrm{t} \mathrm{k/} \mathrm{in} \mathrm{comparable} \mathrm{corpora} \mathrm{of}$ Spanish and Central Catalan (the affricate $/ \mathrm{t} /$, which is also shared by both languages does not seem to voice in Iberian Spanish, although it is frequently voiced in Canary Island Spanish, where it has a more retracted realization, with less friction, Trujillo 1980). The hypothesis of contrast preservation would predict 
that, even if, when compared to Catalan, Spanish shows a greater general tendency to lenite its intervocalic voiceless obstruents, the difference between the two languages should be greater for /s/ than for other phonemes (due to the presence of / $z /$ in Catalan, but not in Spanish).

In sum, whereas our experimental results are consistent with the predictions of the principle of contrast preservation, we cannot discard alternative explanations that do not appeal to this functional principle. A more extensive study of intervocalic lenition in the two languages may shed light on this issue.

Finally, we would like to point out that, as mentioned above, in Catalan, in some lexical items we find dialectal or individual variation in their realization with /s/ or with /z/ (Recasens 1993:173-175). In particular, some words like impressora 'printer' and disseny 'design', in which the standard spelling suggests /s/, are systematically realized with /z/, instead, by some speakers. In the Catalan corpus that we have analyzed, although complete voicing of /s/ is very rare, we did find 20 tokens of fully voiced /s/ (see section 4.1). For instance, if we choose the lexical item with the greatest number of fully voiced realizations, out of 29 tokens of the form passes 'you pass, go' in our corpus, 7 were produced as fully voiced. The occurrence of "unintended" fully voiced tokens of /s/ may lead to phonemic recategorization in specific lexical items, as envisioned in Ohala's framework (see, 
e.g. Ohala 1974). That is, contrast preservation, in the best of cases, cannot be understood as an absolute principle, preventing phoneme recategorization in specific lexical items.

\subsection{Word-position effects}

Regarding our second main result, the weaker character of word-final /s/, which confirms the findings in Torreira \& Ernestus (2012), several facts may also explain it. First of all, there is an important articulatory difference between, on the one hand, /VCV/ and /V\#CV/, and, on the other, NC\#V/. In the former case, the consonant is syllabified in the onset of the syllable, and is thus timed to start in phase with the following vowel (Nam et al. 2009), whereas in /VC\#V/ lexical syllabic affiliation may result in a different gestural coordination, even if, as it is generally assumed for Spanish and Catalan, there is postlexical resyllabification. The prediction of the articulatory phonology view is that intervocalic/s/ will be more reduced word-finally than in other positions.

In this respect, the voicing and weakening of $/ \mathrm{s} /$ in our Madrid Spanish data may also be connected with the phenomenon of "/s/-aspiration" in a large number of Spanish dialects. In fact, the findings of our study may contribute towards an explanation of some seemingly puzzling facts regarding the context of $/ \mathrm{s} /$ aspiration. As already mentioned, in many Spanish varieties, both in 
Spanish and Latin America, /s/ may be realized as [h] or deleted when syllablefinal, either preceding a consonant, as in /éste/ [éhte] 'this', /dós tóros/ [dóhtóroh] 'two bulls', or before pause, as in /dós/ [dóh] 'two'. Interestingly, a very common state of affairs is for aspiration to also take place in word-final position before a vowel, /dós animáles/ [dóhanimáleh] 'two animals', but not in other intervocalic contexts, /kósa/ [kósa] not **[kóha] 'thing' (although there are a few dialects where aspiration is also possible in this environment, see, e.g., Lipski 1986, 1994, Hualde 2005: 161-165).

a.

The application of aspiration in for instance, más amor [má.ha.mór] 'more love' but not in mașa [má.sa] 'dough, mass' in many Spanish dialects requires an explanation, since in both cases we seem to have the same phonological string /ása/.

Within Generative Phonology, the explanation that has been given involves rule ordering and cyclic application of rules (Harris 1983, among others). The context for aspiration in the relevant dialects is the coda of the syllable, but reapplication of a syllabification rule places the consonant in syllable-initial position at a later point in the derivation: /más. \# a.mór/ $\rightarrow$ [máh.a.mór] (by 
aspiration in the coda) $\rightarrow$ [má.ha.mór] (by resyllabification) 'more love'. In /mása/ 'dough, mass', on the other hand, there is no step in the derivation where $/ \mathrm{s}$ / is syllabified in the coda, which prevents it from being aspirated, since the rule targets only coda consonants.

Within an exemplar model, Bybee (2000) provides an explanation that appeals to connections between stored tokens of the same lexical items. She surmises that in Spanish the phonetic context for /s/-aspiration, where the sound change arose, is the preconsonantal one. As noted before, in Madrid Spanish, the dialect that we analyze here, aspiration of $/ \mathrm{s} /$ is rare before a vowel and also before pause, but common before certain consonants. Aspiration of word-final prevocalic/s/ would be an extension from the word-final preconsonantal context to other word-final positions by a sort of analogy, with tokens of a word in the context of aspiration affecting the realization of tokens in other contexts. This extension of aspiration from its original preconsonantal context would be due to the fact that $\mathrm{Ns \# C/}$ is more frequent than $/ \mathrm{Vs} \mathrm{V} /$ or $/ \mathrm{Ns} \# /$. To give an example, the frequent occurrence of the word dos 'two' before a consonant, where it is in the context of lenition, as in do[h] toros 'two bulls', would affect the mental storage of this word as having an aspirated consonant, so that the variant with [h] is chosen even before a vowel, as in do[h] animales 'two animals'. 
Here we would like to suggest another explanation for the aspiration of /s/

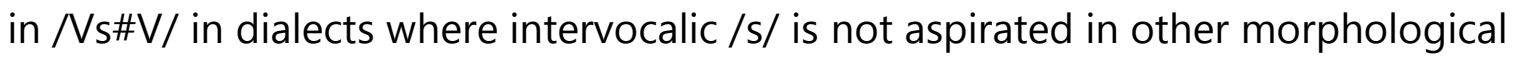
contexts. Our experimental results show that, even in the absence of aspiration, word-final intervocalic /s/ is also weaker than word-medial or word-initial /s/ (confirming the findings in Torreira \& Ernestus 2012). We can thus offer an alternative explanation that does not require cyclic application of rules or an appeal to analogical influence across phonological contexts: /s/-aspiration is a further development in those contexts where /s/ is already weak. It would be the lack of systematic "in-phase" coordination of /s/ with a following vowel (in Articulatory Phonology terms, Nam et al. 2009) that facilitates the weakening of /s/ and its eventual aspiration. In sound change: /VC\#V/ may differ from /VCV/ and $/ \mathrm{V \# CV/} \mathrm{because} \mathrm{of} \mathrm{a} \mathrm{difference} \mathrm{in} \mathrm{gesture} \mathrm{coordination} \mathrm{patterns.} \mathrm{A}$ transcription of, e.g.., más amor as [má.sa.mór], with the same sequence of symbols and the same syllable structure as masa [má.sa] simple offers an incomplete view of phonetic reality.

Again, we cannot exclude the possibility that the explanation for the weak character of word-final prevocalic /s/ in Spanish may also be of a historical nature. Old Spanish most likely was like Catalan and Portuguese in presenting systematic voicing of word-final /s/ before a vowel in the following word. In fact, Judeo-Spanish. which has preserved the Old Spanish contrast between /s/ and /z/ 
in word-medial position, has this distribution (Sala 1971, Hualde \& Şaul 2011). Voicing of intervocalic word-final fricatives is also attested in few Spanish dialects spoken in Spain that had maintained the voice contrast until the first decades of the 20th century, such as that of Malpartida de Plasencia in Extremadura (Catalán 1954, Hualde 1992). We also note that Ecuadorian Spanish, which, like all other Latin American Spanish dialects, lacks phonemic /z/, has been described as presenting systematic voicing of word-final /s/ when followed by a vowel (Lipski 1989). Although the traditional understanding is that the phonemic contrast between /s/ and /z/ was neutralized by systematic devoicing of /z/ both wordmedially, where /z/ previously contrasted with /s/, and word-finally, where there was no contrast, a more nuanced view may be that, although the two phonemes did merge, with loss of the lexical distribution of $/ \mathrm{s} /$ and $/ \mathrm{z} /$, the historical devoicing process was not complete, so that non-contrastive voicing of $/ \mathrm{s} /$ and a generally weaker articulation in word final position in modern Spanish continues an older phonetic pattern.

To recapitulate: We have found that intervocalic $/ \mathrm{s} /$ is more lenited in Spanish than in Catalan. Althoughthis result is consistent with a principle of contrast preservation operating in Catalan, we have noted that there are alternative, non-functional, explanations of the facts, including diachronic ones. Secondly, we have found that in Spanish intervocalic $/ \mathrm{s} /$ is shorter and more 
prone to voicing when word final than in other contexts. We have explained this apparent effect of morphological structure in terms of articulatory coordination. We have pointed out that this result is also compatible with other aspects of the sound pattern of Spanish and dialectal developments, and, in fact, helps us understand why aspiration takes places in $/ \mathrm{Vs} \# \mathrm{~V} /$ in preference to other intervocalic contexts.

Acknowledgments

[to be added]

References

Allen, W. S.: Vox latina: The pronunciation of Classical Latin, $2^{\text {nd }}$ ed. Cambridge: (Cambridge Univ. Press, Cambridge, 1978).

Anderson, A.; Bader, M.; Bard, E. G.; Boyle, E.; Doherty, G.; Garrod, S.; Isard, S.; Kowtko, J.; McAllister, J.; Miller, J.; Sotillo, C.; Thompson, H.: The HCRC Map Task Corpus. Language and Speech, 34(4): 351-366 (1991).

Blecua, B.; Rost, A.: Perception and production of Spanish /f/: the role of the listener. Poster presented at Phonetics and Phonology in Iberia 10, Lisbon (2013). 
Boersma, P.: Functional phonology: Formalizing the interactions between articulatory and perceptual drives. (Holland Academic Graphics, The Hague, 1998).

Boersma, P.; Weenink, D.: Praat: doing phonetics by computer [Computer program]. Version 5.3.39, retrieved 6 January 2013 from http://www.praat.org/ (2013).

Brown, E.: Paradigmatic peer pressure: Word-medial syllable /s/ lenition in Dominican Spanish. In Alvord, Selected Proceedings of the 5th Conference on Laboratory Approaches to Romance Phonology, 46-58. (Cascadilla Proceedings Project, Somerville, MA, 2011).

Brown, G.; Anderson, A.; Yule, G.; Shillcock, R.: Teaching talk. (Cambridge Univ. Press, Cambridge, 1983).

Bybee, J.: Lexicalization of sound change and alternating environments. In Broe, Pierrehumbert, Papers in Laboratory Phonology V: Acquisition and the lexicon, 250-268. (Cambridge University Press, Cambridge, 2000).

Catalán, D.: Concepto lingüístico del dialecto 'chinato' en una chinato-hablante. Revista de Dialectologia y Tradiciones Populares 10: 10-28 (1954).

File-Muriel, R.; Brown, E.: The gradient nature of s-lenition in Caleño Spanish. Language Variation and Change 23: 223-243 (2011).

Flemming, E.. 1996. Evidence for Constraints on Contrast: The Dispersion Theory 
of Contrast. In UCLA Working Papers in Phonology 1, ed. by Chai-Shune Hsu, 86-106 (1996).

Fontanella de Weinberg, M.B.: Dinámica social de un cambio. (UNAM, Mexico, 1979).

Fontanella de Weinberg, M. B.: 1987. El español bonaerense: Cuatro siglos de evolución lingüística (1580-1989). (Hachette, Buenos Aires,1979).

Fougeron, C.; Keating, P.: Articulatory strengthening at edges of prosodic domains. J. Acoust. Soc. Am. 101, 3728-3740 (1997).

Gurevich, N. Lenition and Contrast: The Functional Consequences of Certain Phonetically Conditioned Sound Changes (Outstanding Dissertations in Linguistics). (Routledge, New York, 2004).

Gussenhoven, C.; Wang, L.: Yuhuan Wu tone and the role of sonorant onsets. Proc. Speech Prosody 7, 619-622, Dublin, 2014.

Harris, J.: Syllable structure and stress in Spanish: A nonlinear analysis. (MIT Press, Cambridge, Mass., 1983).

Hock, H. H.: Principles of historical linguistics, 2nd ed. (Mouton de Gruyter, Berlin, 1991).

Hualde, J. I.: Aspiration and resyllabification in Chinato Spanish. Probus 3.1: 55-76 (1992).

Hualde, J.I.: The sounds of Spanish. (Cambridge Univ. Press, Cambridge, 2005). 
Hualde, J. I.; Nadeu; M.; Simonet, M.: Lenition and phonemic contrast in Majorcan Catalan. In Colina, Olarrea, Carvalho, Romance linguistics 2009: Selected papers from the 39th linguistic symposium on Romance languages, 63-79. (Benjamins, Amsterdam, 2010).

Hualde, J. I.; Nadeu, M.: Lenition and phonemic overlap in Rome Italian. Phonetica 68(4). 215-242 (2011).

Hualde, J. I.; Şaul, M.: Istanbul Judeo-Spanish. J. of the Intern. Phonetic Assoc. 41.1: 89-110 (2011).

Hualde, J. I.; Simonet M.; Nadeu, M.: Do words or phonemes change? Evidence from lenition processes in progress. Poster presented at Workshop on Sound Change, Barcelona, 21-22 Oct. 2010 (2010).

Hualde, J. I.; Simonet, M.; Nadeu, M. Consonant lenition and phonological recategorization. Laboratory Phonology 2.2: 301-329 (2011).

Joseph, B.: Utterance-finality: framing the issue. In Palek, B.; Fujimura, O.; Joseph, B.; Proceedings of $L P^{\prime} 98$, Fourth Linguistics and Phonetics Conference, vol. 2, pp. 3-13. (Karolinum, Prague, 1999),

Lehiste, Ilse (1970). Suprasegmentals. (MIT Press, Cambridge, MA, 1970).

Lewis, A. M.: Weakening of intervocalic /ptk/ in two Spanish dialects: Toward the quantification of lenition processes. Doctoral dissertation, University of Illinois at Urbana-Champaign (2001). 
Lipski, J.: Reduction of Spanish word-final /s/ and /n/. Canadian J. of Linguistics 31: 239-156 (1986).

Lipski, J.: /s/-voicing in Ecuadoran Spanish. Lingua 79: 49-71 (1989).

Lipski, J.: Latin American Spanish (Longman, London and New York, 1994).

Łubowicz, A.: Contrast preservation in phonological mappings. Doctoral Diss., Univ. of Massachusetts, Amherst (2003).

Machuca Ayuso, M.J.: Las obstruyentes no continuas del español: relación entre las categorías fonéticas y fonológicas en habla espontánea. Doctoral dissertation, Universitat Autònoma de Barcelona (1997).

Momcilovic, N.: A sociolinguistic analysis of /s/-aspiration in Madrid Spanish. LINCOM, Munich, 2009).

Moreno Fernández, F.: Castilla la Nueva. In Alvar, M., Manual de dialectología hispánica: El español de España, pp. 213-232. (Barcelona: Ariel, Barcelona, 1996).

Nam, H.; Goldstein, L.; Saltzman, E.: Self-organization of syllable structure: A coupled oscillator model. In Peregrino, Marisco, Chitoran, Approaches to phonological complexity, pp. 299-328. (Mouton de Gruyter, Berlin, 2009).

Oftedal, M.: Lenition of stops in Celtic and in Insular Spanish: The second voicing of stops in Gran Canaria. (Universitetsforlaget, Oslo, 1985). 
Ohala, J.: Experimental historical phonology; in Anderson, Jones, Historical linguistics, vol. 2, pp. 353-389 (North Holland, Amsterdam 1974).

Ohala, J.: The origin of sound patterns in vocal tract constraints. In MacNeilage, P., The Production of Speech, pp. 189-216. New York: Springer, New York, 1983).

O'Neill, P.: Variación y cambio en las consonantes oclusivas del español de Andalucía. Estudios de Fonética Experimental 19: 11-41 (2010).

Ortega-Llebaria, M.: Interplay between phonetic and inventory constraints in the degree of spirantization of voiced stops: Comparing intervocalic /b/ and intervocalic /g/ in Spanish and English. In Face, T., Laboratory approaches to Spanish phonology, pp. 237-253 (Mouton de Gruyter, Berlin, 2004).

Pape, D.; Jesus, L. M.T.: Devoicing of phonologically voiced obstruents: Is European Portuguese different from other Romance languages?, Proc. of the 17th ICPhS, Hongkong, China (2011).

Penny, R.: A history of the Spanish language, $2^{\text {nd }}$ ed. (CUP, Cambridge, 2002).

Pons Moll, C.: La teoria de l'optimitat: Una introducció aplicada al català de les Illes Balears. (Publicacions de l'Abadia de Montserrat, Barcelona, 2007).

Prieto, P. ; Roseano, P.: Atlas interactivo de la entonación del español. Webpage: http://prosodia.upf.edu/atlasentonacion/ (2009-2013).

Prieto, P.; Cabré, T.: Atles interactiu de l'entonació del català. Webpage: http://prosodia.upf.edu/atlesentonacio/ (2007-2012). 
Rafel, J.: Fonologia diacrònica catalana: Aspectes metodològics. Problemes de Ilengua i literatura catalanes: Actes del II col.loqui internacional sobre el català, pp. 47-65. (Publicacións de l'Abadia de Montserrat, Montserrat, 1976).

Recasens, D.: Notes entorn del rendiment fonològic de l'oposició /b/-/v/ al Tarragonès: estat actual. Estudis Romànics 16: 163-183 (1971/1975).

Recasens, D.: Fonètica descriptiva del català (Assaig de caracterització de la pronúncia del vocalisme i consonantisme del català al segle XX). (Institut d'Estudis Catalans, Barcelona, 1991).

Recasens, D.: Fonètica i fonologia. (Enciclopèdia Catalana, Barcelona, 1993).

Recasens, D.: Fonètica descriptiva del català (Assaig de caracterizatzió de la pronúncia del consonantisme català al segle $X X$ ), $2^{\text {nd }}$ ed. (Institut $d^{\prime} E s t u d i s$ Catalans, Barcelona, 1996).

Recasens, D.: Weakening and strengthening in Romance revisited. Rivista di Linguistica 14.2: 327-373 (2002).

Recasens, D.: Sobre la rellevància del detall articulatori i acústic en l'explicació del canvi fonètic. In Rafel, D., Diachronic linguistics, pp. 115-134. (Editorial Documenta Universitaria, Girona, 2009).

Recasens, D.: Fonètica i fonologia experimentals del català. Vocals $i$ consonants. (Institut d'Estudis Catalans, Barcelona, 2014). 
Rivas, M.V.: Does the perception of fricatives correspond to their production? The case of Italian vs. Dutch. MA thesis, Univ. of Amsterdam (2006).

Rohena-Madrazo, M.: Variación y cambio de sonoridad de la fricativa postalveolar del español de Buenos Aires. In Colantoni, Rodríguez Louro, Perspectivas teóricas y experimentales sobre el español de la Argentina, pp. 37-57. (Iberoamericana/Vervuert, Madrid/Frankfurt, 2013).

Sala, M.: Phonétique et phonologie du judéo-espagnol de Bucarest. (Mouton, The Hague, 1971).

Schmidt, L.; Willis, E.: Systematic investigation of voicing assimilation of Spanish /s/ in Mexico City. In Alvord, , Selected Proceedings of the 5th Conference on Laboratory Approaches to Romance Phonology, 1-20. (Cascadilla Proceedings Project, Somerville, MA, 2011).

Smith, C.: The devoicing of /z/ in American English: effects of local and prosodic context. J. of Phonetics 25: 471-500 (1997).

Solé, M.-J.: Assimilatory processes and aerodynamic factors. In Gussenhoven, Warner, Papers in Laboratory Phonology 7: 351-381. (Mouton de Gruyter, Berlin, 2002).

Torreblanca, M. : La sonorización de las oclusivas sordas en el habla toledana. Boletín de la Real Academia Española 56(207): 117-146 (1976). 
Torreira, F.; Ernestus, M.: Realization of voiceless stops and vowels in conversational French and Spanish. Laboratory Phonology 2: 331-353 (2011).

Torreira, F.; Ernestus, M.: Weakening of intervocalic/s/ in the Nijmegen Corpus of Casual Spanish. Phonetica, 69: 124-148 (2012).

Trask, R. L.: Historical linguistics. (Arnold, London, 1996).

Trujillo, R.: Sonorización de sordas en Canarias. Anuario de Letras 18: 247-254.

Wedel, A.: Lexical contrast maintenance and the organization of sublexical contrast systems. Language and Cognition 4: 319-355 (2012).

Wedel, A.; Kaplan, A.; Jackson, S.: High functional load inhibits phonological contrast loss: A corpus study. Cognition 128.2: 179-186 (2013).

Wheeler, M.: The phonology of Catalan. (OUP, Oxford, 2005).

Figure captions

Figure 1. Percentage of fully voiced tokens of $/ \mathrm{s} /$ by position in our Spanish corpus.

Figure 2. Percentage of fully voiced tokens of $/ \mathrm{s} /$ by position in our Catalan corpus. 
Figure 3. Percentage of fully voiced and partially devoiced tokens of /z/ and intervocalic word-final /S/ in our Catalan corpus.

Figure 4. Mean percentage of voiced frames of intervocalic /s/ segments of Spanish and /s/ and /z/ segments in Catalan (ranging from 0 to 1 ) as a function of the position within the word (initial, medial, final) in the Spanish and Catalan Map Task corpora. Note that medial_z represents word-medial /z/ in Catalan.

Figure 5. Mean duration of $/ \mathrm{s} /$ (in $\mathrm{ms}$ ) as a function of the position of the consonant within the word (initial, medial, final) in the Spanish and Catalan data (represented in the $x$ axis). Note that medial_z represents the duration of wordmedial /z/ in Catalan. 